\title{
PENGARUH MODEL ELICITING ACTIVITIES (MEA'S) TERHADAP HIGHER ORDER THINKING SKILLS (HOTS) DAN SELF ESTEEM SISWA SEKOLAH MENENGAH PERTAMA
}

\author{
The Effect of Model Eliciting Activities (MEAs) to Higher Order Thinking Skills \\ (HOTS) and Self Esteem of Junior High School Students
}

\author{
Deta Edias Pangestika \\ Jurusan Pendidikan Matematika, Jenjang Magister Universitas Negeri Jakarta, Daerah Khusus Ibukota \\ Jakarta, \\ dettaedias@gmail.com
}

\begin{abstract}
This research aims to know the effect of Model Eliciting Activities (MEAs) and Conventional Learning Models to Higher Order Thinking Skills (HOTS) in mathematics and students self-esteem.The research was conducted at SMPN 200 and SMPN 53 Jakarta in the academic year 2020/2021. Design of this research is a post-test only experiment and control group design. The method used in this research was a quasi experiment. The instruments consist of the Higher Order Thinking Skills test, prior knowledge of mathematics test, and a questionnaire of mathematics self-esteem. The instruments have been checked in terms of validity and reliability. Two-way Anova was used for data analysis. The results show that: (1) Higher Order Thinking Skills of students who are given MEA's is higher than the students who are given conventional Learning Models. (2) There is an enhancement of Higher Order Thinking Skills of students effected by prior knowledge of mathematics and Mathematics Learning Models. (3) Higher Order Thinking Skills of students with high KAM who are given MEA is higher than the students who are given Conventional Learning Model. (4) There is no significant difference in terms of Higher Order Thinking Skills between students with low KAM given MEA treatment and students given Conventional Learning Model treatment. (5) Mathematics Self Esteem of students given MEA treatment is higher than those given Conventional Learning Model treatment.
\end{abstract}

Keyword: HOTS, Model Eliciting Activities (MEA's), self esteem

\begin{abstract}
ABSTRAK
Penelitian ini bertujuan untuk mengetahui pengaruh Model Eliciting Activities (MEA's) dan konvensional terhadap Higher Order Thinking Skills (HOTS) dan self esteem siswa. Penelitian ini dilaksanakan di SMPN 200 dan SMPN 53 Jakarta tahun ajaran 2020/2021. Desain penelitian ini adalah post-test eksperimen dan kontrol grup desain. Metode penelitian yang digunakan adalah metode quasi experiment (eksperimen semu). Instrumen yang digunakan terdiri dari tes Higher Order Thinking Skills (HOTS), tes Kemampuan Awal Matematika (KAM) dan angket self esteem matematika. Instrumen tersebut telah melalui uji validitas dan reliabilitas. Analisis data dilakukan dengan uji Anava dua jalur. Berdasarkan hasil penelitian, ditemukan bahwa: (1) Higher Order Thinking Skills siswa yang belajar dengan MEA's lebih tinggi dibandingkan Higher Order Thinking Skills siswa yang belajar dengan model konvensional. (2) terdapat peningkatan Higher Order Thinking Skills siswa yang dipengaruhi oleh kemampuan awal matematika dan model pembelajaran (3) Higher Order Thinking Skills siswa yang diberi perlakuan MEA's lebih tinggi dibandingkan dengan siswa yang diberi perlakuan model konvensional pada kelompok siswa yang memiliki kemampuan awal matematika tinggi. (4) tidak terdapat perbedaan Higher Order Thinking Skills siswa antara siswa yang diberi perlakuan dengan MEA's dan siswa yang diberi perlakuan model konvensional pada kelompok siswa yang memiliki kemampuan awal matematika rendah. (5) self esteem siswa dalam belajar matematika yang diberi perlakuan MEA's lebih tinggi dibandingkan dengan self esteem siswa yang diberi perlakuan model konvensional.
\end{abstract}

Kata Kunci: HOTS, Model Eliciting Activities (MEA’s), self esteem

\section{PENDAHULUAN}

Model pembelajaran yang berkembang saat ini khususnya pada matematika merekomendasikan proses pembelajaran yang membuat siswa aktif. Pembelajaran yang menekankan peran aktif siswa 
dalam membentuk pengetahuan dapat mengembangkan proses berpikir siswa. Menurut Piaget (1983) yang memandang bahwa setiap individu memiliki kemampuan sendiri untuk mengembangkan pengetahuannya dengan cara berinteraksi terus menerus dengan lingkungannya. Model-model pembelajaran yang menunjang Kurikulum di Indonesia juga sudah banyak yang menerapkan pendekatan dengan menekankan peran aktif siswa.

Pembelajaran Model-Eliciting Activities (MEA's) adalah suatu model pembelajaran yang menekankan peran aktif siswa dan melatih siswa untuk membuat model sendiri dalam menyelesaikan permasalahan pada soal matematika. Model-Eliciting Activities (MEA's) merupakan model pembelajaran yang memfokuskan aktivitas siswa untuk mendapatkan atau memperoleh penyelesaian dari masalah yang diberikan melalui proses mengaplikasikan prosedur matematis untuk membentuk sebuah model matematika. Penciptaan suatu model matematis membutuhkan suatu konsep yang kuat tentang pemahaman masalah sehingga dapat membantu siswa menuangkan ide-ide mereka (Chamberlin dan Moon, 2005). Pembelajaran matematika dengan Model-Eliciting Activities (MEA's) merupakan suatu pilihan pendekatan yang berupaya membuat siswa dapat secara aktif untuk terlibat dalam proses pembelajaran matematika di kelas.

Lesh dan Doerr (2003) mengatakan bahwa Model Eliciting Activities (MEA's) adalah kegiatan membangun model dari perspektif pemodelan untuk memecahkan suatu masalah dalam pendidikan matematika, ilmu pengetahuan dan teknik dengan pendekatan pembelajaran yang berorientasi masa depan. Permana (2010) juga menyatakan bahwa Model Eliciting Activities (MEA's) merupakan proses pembelajaran yang mengharapkan siswa untuk dapat mengkontruksi model matematis. Model yang dibuat tidak hanya berupa konsep baru dalam matematika, yang terpenting adalah benar-benar asli dari hasil pemikiran siswa dan merupakan susatu yang baru bagi siswa. Chamberlin dan Moon (2005) menyebutkan karakteristik Model-Eliciting Activities (MEAs) yang dirancang dengan 6 prinsip. Keenam prinsip tersebut antara lain: prinsip realitas, prinsip konstruksi model, prinsip penilaian diri, prinsip konstruksi dokumentasi model, prinsip prototipe sederhana, dan yang terakhir prinsip konstruksi kemampuan untuk dipakai bersama dan digunakan kembali.

Peraturan Menteri Pendidikan dan Kebudayaan Nomor 22 Tahun 2016 sesuai dengan Standar Kompetensi Lulusan, sasaran pembelajaran mencakup pengembangan ranah sikap, pengetahuan, dan keterampilan yang dielaborasi untuk setiap satuan pendidikan. Jika dikaitkan dengan tingkat taksonomi Bloom, yakni remembering (mengingat), understanding (memahami), applying (menerapkan), analyzing (menganalisis), evaluating (mengevaluasi), dan creating (mencipta), maka untuk mengembangkan ranah pengetahuan dan keterampilan yang terdapat pada Standar Kompetensi Lulusan yang diperoleh dari aktivitas menganalisis, mengevaluasi, dan mencipta tentunya seorang siswa membutuhkan keterampilan berpikir tingkat tinggi atau Higher Order Thinking Skills (HOTS).

Kemampuan berpikir tinggi mendorong siswa untuk menginterpretasikan, menganalisa atau bahkan mampu memanipulasi informasi sebelumnya sehingga tidak monoton. Kemampuan berpikir tingkat tinggi digunakan apabila seseorang menerima informasi baru dan menyimpannya untuk kemudian digunakan atau disusun kembali untuk keperluan pemecahan masalah (Ariandari, 2015). Higher Order Thinking Skills (HOTS) dapat dilatihkan kepada siswa melalui pembelajaran. Anderson \& Krathwohl (2001) menyebutkan bahwa terdapat indikator untuk mengukur High Order Thinking Skills (HOTS) meliputi (1) Analyzing (menganalisis) yaitu mendeteksi bagaimana suatu bagian materi berhubungan dengan bagian materi yang lain (2) Evaluating (mengevaluasi) yaitu membuat keputusan dengan cara memeriksa dan mengkritik (3) Creating (menciptakan) yaitu menempatkan elemen bersama-sama untuk membentuk suatu keseluruhan yang membuat hasil yang asli, seperti menyusun, merencanakan dan menghasilkan.

Ujian Nasional (UN) pada tahun 2018-2019 telah mengukur ranah kognitif siswa yang lebih tinggi dimana beberapa soal yang dikembangkan berorientasi untuk dapat mengasah kemampuan pemecahan masalah dan penalaran siswa. Hal tersebut dipertegas oleh Menteri Pendidikan dan Kebudayaan yang pernah mengungkapkan bahwa Ujian Nasional (UN) akan diterapkan soal dengan level Higher Order Thinking Skill (HOTS). Kemudian Ujian Nasional (UN) ditiadakan pada tahun 2020 karena adanya pandemi COVID-19, pemerintah melalui kemendikbud kembali meniadakan 
UN di tahun 2021 untuk fokus memeperbaiki mutu pendidikan dan menggantinya dengan Asesmen Nasional (AN) yang salah satu bagiannya adalah Asesmen Kompetensi Minimum (AKM). AKM ini dirancang untuk mengukur hasil belajar kognitif (literasi dan numerasi) peserta didik. Literasi di sini bukan hanya kemampuan membaca, tetapi kemampuan menganalisis suatu bacaan, dan memahami konsep di balik tulisan tersebut. Sedangkan kompetensi numerasi berarti kemampuan menganalisis menggunakan angka dan mampu menggunakan konsep matematika untuk diterapkan di kehidupan (Mendikbud, 2020). AKM memiliki konten ke arah level kognitif yang lebih tinggi atau Higher Order Thinking Skills (HOTS). Mendikbud mengharapkan perubahan standar kelulusan dari UN menjadi Asesmen Nasional (AN) bisa mendorong perbaikan mutu pembelajaran dan hasil belajar peserta didik di Indonesia. Selain itu, untuk meningkatkan pendidikan agar bisa menjadi bekal bagi generasi muda di masa depan.

Soal dengan daya nalar tinggi atau Higher Order Thinking Skills (HOTS). merupakan sesuatu yang tidak bisa dihindari agar siswa memiliki kemampuan di abad 21. Higher Order Thinking Skills (HOTS) harus dilatihkan kepada siswa dalam proses pembelajaran matematika agar level berpikir siswa meningkat, sehingga siswa mempunyai kontribusi dalam kehidupan sosial bermasyarakat karena dengan Higher Order Thinking Skills (HOTS) dapat mendorong siswa untuk berprestasi di sekolah, dan dapat memberikan kontribusi kepada masyarakat (Conklin, 2012). Pengajaran dan pelatihan tentang Higher Order Thinking Skills (HOTS) saat ini menjadi pusat perhatian pada pendidikan, khususnya untuk kurikulum matematika di sekolah menengah saat ini telah bergeser pada pengembangan Higher Order Thinking Skills (HOTS). Harapan ke depan dan dimulai dari sekarang khususnya pembelajaran matematika di Indonesia, pengembangan Higher Order Thinking Skills (HOTS) hendaknya menjadi bagian dalam penilaian di kelas.

Pembelajaran dengan Model-Eliciting Activities (MEA's) yang telah dijelaskan sebelumnya mempunyai tujuan agar siswa lebih memahami dalam memecahkan suatu masalah matematika, yaitu dengan mendorong siswa membangun model sendiri untuk menyelesaikan suatu permasalahan yang kompleks menurut sudut pandang masing-masing siswa. Dengan terlibatnya siswa secara aktif dalam proses pembelajaran menggunakan Model-Eliciting Activities (MEAs) diharapkan Higher Order Thinking Skills (HOTS) siswa dapat terlatih dengan baik.

Penerapan pembelajaran dengan menggunakan model Model-Eliciting Activities (MEA's) selain diharapkan dapat mengembangkan Higher Order Thinking Skills (HOTS) siswa, juga diharapkan dapat meningkatkan self-esteem siswa dalam matematika. Meningkatkan self-esteem siswa adalah dengan memberikan tanggung jawab kepada siswa dalam belajar, siswa harus diberikan kesempatan untuk berperan secara aktif dalam belajar, guru harus menciptakan suatu iklim pembelajaran dimana siswa merasa kontribusi mereka dihargai. Mahmud (2010) menyatakan bahwa self-esteem (harga diri) adalah penilaian individu (self-judgement) terhadap kehormatan dirinya, yang diekspresikan melalui sikap terhadap dirinya. Siswa yang merasa dirinya tidak mampu menyelesaikan soal-soal matematika dengan baik, tentunya akan merasa putus asa ataupun tidak mau berusaha belajar matematika dan memahami matematika dengan baik. Hal ini tentu saja akan sangat berpengaruh terhadap prestasi belajar yang mereka capai.

Pembelajaran dengan menggunakan Model-Eliciting Activities (MEA's) menuntut siswa untuk bisa membangun model matematika dari permasalahan yang diberikan dan diharapkan model tersebut dapat dimengerti oleh siswa lain, dengan demikian siswa akan merasa dirinya dibutuhkan, merasa dihargai, dan merasa bangga ide-idenya dapat diterima dengan baik oleh guru beserta temantemannya. Hal tersebut dapat menumbuhkan self-esteem siswa dalam matematika. Ketika self-esteem yang tinggi telah tumbuh dan berkembang dalam diri siswa, maka siswa tidak lagi akan cepat putus asa bila menghadapi soal-soal dengan kemampuan tingkat tinggi atau Higher Order Thinking Skills (HOTS). Proses pembelajaran seperti ini, memungkinkan siswa untuk dapat melatih dan mengembangkan self-esteem matematisnya.

Berdasarkan paparan di atas penulis memandang perlu melakukan suatu penelitian untuk mengetahui secara empiris pengaruh Model Eliciting Activities (MEA's) terhadap Higher Order Thinking Skills (HOTS) dan self esteem matematis siswa SMP Negeri di Kecamatan Cilincing. 


\section{METODE}

Metode yang digunakan dalam penelitian ini adalah metode eksperimen semu (quasi eksperimen). Variabel aktif adalah model pembelajaran yang terdiri dari MEA's (M) dan model pembelajaran konvensional (K). Sedangkan variabel atributnya adalah kemampuan awal terhadap matematika yang terdiri dari kemampuan awal matematika tinggi (T) dan kemampuan awal matematika siswa rendah (R). Variabel terikatnya adalah Higher Order Thinking Skills (HOTS) dan self esteem matematis siswa. Penelitian ini pada aspek kognitif menggunakan metode eksperimen dengan desain faktorial $2 \times 2$ treatment by level dengan empat variabel penelitian, yaitu dua variabel terikat dan dua variabel bebas. Kerangka penelitian yang digunakan pada penelitian ini disajikan dalam bentuk tabel berikut:

Tabel 1. Kerangka Penelitian HOTS ditinjau dari KAM

\begin{tabular}{ccc}
\hline $\begin{array}{c}\text { Kemampuan Awal } \\
\text { Matematika (KAM) }\end{array}$ & \multicolumn{2}{c}{ Model Pembelajaran (MP) } \\
\cline { 2 - 3 } & MEA's (M) & Konvensional (K) \\
\hline Tinggi (T) & MT & KT \\
\hline Rendah (R) & MR & KR
\end{tabular}

Populasi dalam penelitian ini adalah seluruh siswa SMP Negeri di Kecamatan Cilincing tahun pelajaran 2020/2021. Teknik pengambilan sampel yang digunakan pada penelitian ini adalah Memilih secara random sampling SMP Negeri di Kecamatan Cilincing dengan Akreditasi A, sehingga terpilih populasi target yaitu SMPN 200 dan SMPN 53 untuk dijadikan tempat penelitian. Penelitian ini mengundi kelas eksperimen dan kelas kontrol dari semua kelas VII di SMPN 200 dan SMPN 53 yang sudah lulus uji prasyarat analisis. Kemudian memilih dua kelas untuk kelas eksperimen dan dua kelas untuk kelas kontrol dengan menggunakan random sampling. Menentuan kelompok pada penelitian ini dengan cara membentuk kelas eksperimen dan kelas kontrol, kemudian dibagi lagi menjadi dua kelompok dengan KAM tinggi dan KAM rendah, sedangkan kelompok kemampuan awal matematika sedang diabaikan supaya perbedaannya lebih terlihat. Kelompok dengan KAM tinggi dan kelompok KAM rendah ditentukan dengan cara diurutkan dari skor tertinggi ke skor terendah, kemudian menurut Naga (2012) pengambilan secara acak 33,3\% dari urutan teratas untuk siswa KAM tinggi dan 33,3\% dari urutan terbawah untuk siswa KAM rendah dimana angka ini dianggap valid dan reliabel.

\section{HASIL DAN PEMBAHASAN}

Data skor Higher Order Thinking Skills (HOTS) berdasarkan kemampuan awal matematika antara siswa yang diberi perlakuan dengan MEA's dan siswa yang diberi perlakuan dengan model konvensional menggunakan Ms. Office Excel 2013:

Tabel 2. Statistik Deskriptif Data HOTS

\begin{tabular}{ccccc|cccc}
\hline $\begin{array}{c}\text { Kemampuan } \\
\text { Awal } \\
\text { Matematis }\end{array}$ & \multicolumn{4}{c|}{ MEA's } & \multicolumn{4}{c}{ Konvensional } \\
\cline { 2 - 9 } & Min. & Maks. & $\bar{x}$ & SD & Min. & Maks. & $\bar{x}$ & SD \\
\hline Tinggi & 9 & 14 & 11.95 & 1.59 & 8 & 12 & 10.05 & 1.33 \\
\hline Rendah & 5 & 11 & 8.05 & 1.68 & 5 & 11 & 7.86 & 1.55 \\
\hline Jumlah & & & 20.00 & 3.26 & & & 17.91 & 2.88 \\
\hline
\end{tabular}

Berdasarkan hasil tes HOTS siswa yang diberi perlakuan dengan Model MEA's memperoleh ratarata skor 11,95, sedangkan hasil tes HOTS siswa yang diberi perlakuan dengan model konvensional memperoleh rata-rata skor 10,05. Kedua kelas tersebut menggunakan jumlah sampel masing-masing sebanyak 44 siswa. Berdasarkan tabel di atas, terlihat bahwa rata-rata skor tes HOTS siswa pada kelas eksperimen lebih tinggi dibandingkan dengan rata-rata hasil belajar siswa pada kelas kontrol. 
Hal tersebut mengindikasikan bahwa pembelajaran dengan MEA's memiliki keunggulan dibandingkan dengan model konvensional.

Hasil analisis data yang diperoleh setelah penelitian pada hipotesis pertama menunjukan bahwa nilai nilai $F_{\text {hitung }}=10,127$ dengan $p$-value $=0,002$, karena 0,002 $<0,05$ maka terdapat perbedaan yang signifikan pada Higher Order Thinking Skills siswa jika dikelompokan berdasarkan kemampuan awal matematika. Secara keseluruhan pengujian hipotesis yang pertama membuktikan bahwa adanya perbedaan yang signifikan antara Higher Order Thinking Skills yang ditinjau dari KAM dengan diberi perlakuan Model MEA's dan konvensional. Hal ini membuktikan bahwa Higher Order Thinking Skills siswa yang diberi perlakuan dengan model MEA's lebih tinggi dibandingkan dengan siswa yang diberi perlakuan dengan model konvensional.

Hasil analisis data hipotesis kedua menunjukan adanya interaksi antara model pembelajaran dan KAM yang berpengaruh terhadap Higher Order Thinking Skills siswa. Berpengaruhnya interaksi berarti model pembelajaran dan KAM secara bersama-sama memberikan pengaruh yang signifikan terhadap Higher Order Thinking Skills siswa atau peningkatan Higher Order Thinking Skills siswa dipengaruhi oleh kemampuan awal matematika dan model pembelajaran. Interaksi antara kemampuan awal matematika dan model pembelajaran terhadap Higher Order Thinking Skills dapat divisualisasikan melalui gambar berikut.

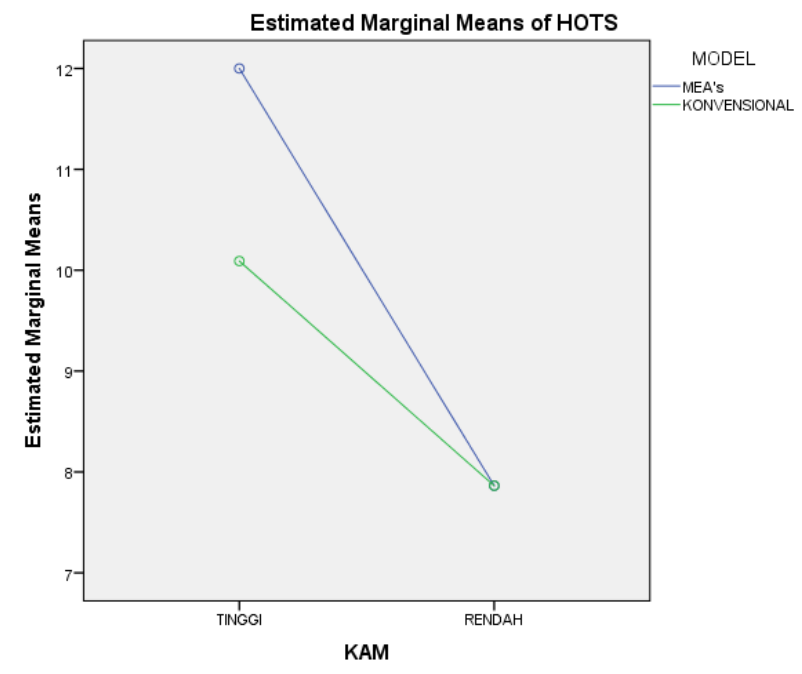

Gambar 1. Estimated Marginal Means of Higher Order Thinking Skills

Hasil analisis data hipotesis ketiga menunjukan bahwa Higher Order Thinking Skills siswa yang diberi perlakuan dengan model MEA's lebih tinggi dibandingkan dengan siswa yang diberi perlakuan dengan model konvensional pada siswa yang berkemampuan awal tinggi. Berdasarkan hasil analisis data, dilihat dari $t_{\text {hitung }}=4,328$ pada taraf signifikansi $\alpha=0,05$ dengan $\mathrm{dk}=42$, bila dicocokan dengan nilai $t_{\text {tabel }}=1,68$, karena $t_{\text {hitung }}$ lebih dari $t_{\text {tabel }}$. Hal ini terjadi karena pada siswa berkemampuan awal tinggi yang diberi perlakuan dengan model MEA's mampu mengembangkan Higher Order Thinking Skills, sehingga pembelajaran menjadi lebih baik. Praptiwi dan Handika (2012) mengemukakan bahwa kemampuan awal akan mempengaruhi keberhasilah siswa dalam pembelajaran atau tidak. Kemampuan awal sangat penting bagi siswa dalam menerima pengetahuan baru. Dengan demikian siswa yang memiliki kemampuan awal yang tinggi akan lebih mudah memahami pengetahuan baru.

Hasil analisis data hipotesis keempat menunjukkan hasil nilai $t_{\text {hitung }}=0,373$ pada taraf signifikansi $\alpha=0,05$ dengan $d k=42$, bila dicocokan dengan nilai $-t_{\text {tabel }}=1,68$, karena $t_{\text {hitung lebih dari }}$ $-t_{\text {tabel }}$ berarti tidak ada perbedaan rata-rata Higher Order Thinking Skills pada kelompok siswa yang 
memiliki kemampuan awal rendah, baik diberi perlakuan dengan MEA's maupun dengan model konvensional. Hal ini terjadi karena siswa yang memiliki KAM rendah belum memahami materi dasar matematika sehingga siswa sulit untuk membangun pengetahuan baru dalam memecahkan masalah.

Hasil analisis data hipotesis kelima baik dari analisis deskriptif maupun uji statistik, menunjukan bahwa adanya perbedaan yang signifikan antara self esteem yang diberi perlakuan dengan model MEA's dengan siswa yang diberi perlakuan dengan model konvensional. Hal ini menunjukan bahwa self esteem siswa dalam belajar matematika yang diberi perlakuan dengan model MEA's lebih tinggi dibandingkan dengan siswa yang diberi perlakuan dengan model konvensional. Seorang guru pada pembelajaran MEA's memberikan apresiasi yang baik kepada siswa yang berhasil menemukan solusi dari model yang telah dibangun atau diciptakan, sehingga siswa merasa dirinya akan dihargai. Semua pendapat dan ide yang telah siswa berikan akan direspon oleh guru dan siswa lainnya, jadi siswa tidak merasa disia-siakan. Pada kelas konvensional yang mendapat perlakuan pembelajaran model konvensional siswa kurang mengembangkan self esteem. Karena pada proses ini siswa hanya cenderung menerima materi yang diberikan guru. Guru kurang memberikan ruang untuk menyukai matematika dan menunjukkan bahwa matematika sangat bermanfaat dalam kehidupan sehari-hari. Dalam merencanakan pembelajaran guru juga kurang memperhatikan minat siswa. Seperti yang diungkapkan oleh Jensen dan Nickelsen (2008) bahwa siswa menyukai matematika dan menunjukkan bahwa matematika sangat bermanfaat dalam kehidupan sehari-hari, memperhatikan minat siswa ketika merencanakan pengajaran, menyediakan pengalaman matematis di mana siswa dapat berhasil, serta membuat matematika dapat dipahami yaitu dengan metode pembelajaran yang efektif dan bermakna.

\section{SIMPULAN DAN SARAN}

Berdasarkan hasil pengujian hipotesis dan pembahasan penelitian, dapat disimpulkan bahwa (1) Higher Order Thinking Skills siswa yang belajar dengan Model Eliciting Activities (MEA's) lebih tinggi dari Higher Order Thinking Skills siswa yang belajar dengan model pembelajaran Konvensional. (2) Terdapat peningkatan ke Higher Order Thinking Skills siswa yang dipengaruhi oleh kemampuan awal matematika dan model pembelajaran (3) Higher Order Thinking Skills siswa yang diberi perlakuan Model Eliciting Activities (MEA's) lebih tinggi dibandingkan dengan siswa yang diberi perlakuan model pembelajaran Konvensional pada kelompok siswa yang memiliki kemampuan awal matematika tinggi. (4) Tidak ada perbedaan Higher Order Thinking Skills siswa yang diberi perlakuan Model Eliciting Activities (MEA's) dengan siswa yang diberi perlakuan model pembelajaran konvensional pada kelompok siswa yang memiliki kemampuan awal matematika rendah. (5) Self esteem siswa dalam belajar matematika yang diberi perlakuan Model Eliciting Activities (MEA's) lebih tinggi dibandingkan dengan siswa yang diberi perlakuan model pembelajaran Konvensional.

Berdasarkan hasil penelitian, diberikan beberapa saran, yaitu sebaiknya dalam menyampaikan materi matematika guru perlu memperhatikan model pembelajaran yang akan digunakan terutama berdasarkan tahapan model pembelajaran tersebut. Guru hendaknya dapat memilih model pembelajaran yang tepat untuk meningkatkan kemampuan siswa, baik kemampuan aspek kognitif ataupun kemampuan aspek afektif siswa. Salah satu model pembelajaran yang dapat meningkatkan kemampuan siswa adalah model pembelajaran MEA's. Kemampuan mengembangkan model pembelajaran di sekolah sangat perlu dilakukan oleh guru, hal ini sebagai langkah terbaik untuk mengatasi kejenuhan yang dialami siswa dalam belajar. Persiapan yang matang sebelum proses pembelajaran juga diperlukan, baik dari persiapan media yang akan digunakan, persiapan diri dalam melaksanakan langkah-langkah pembelajaran maupun waktu yang digunakan agar pembelajaran berjalan dengan lancar dan menyenangkan.

Guru juga perlu mengetahui bahwa kemampuan awal tiap siswa dalam satu kelas tidak sama. Oleh karena itu guru dapat membantu siswa dalam mengoptimalkan kemampuan awal yang dimililki 
sehingga tujuan pembelajaran dapat tercapai. Model pembelajaran yang diterapkan oleh guru juga diharapkan mampu memberikan perlakuan yang sama sesuai dengan karakteristik siswa, misalnya kemampuan awal yang dimiliki oleh siswa. Model pembelajaran yang hendaknya memiliki langkahlangkah belajar yang sekiranya dapat melibatkan seluruh kelas dalam belajar, tidak hanya yang memiliki kemampuan awal tinggi, tetapi juga untuk siswa yang memiliki kemampuan awal rendah. Guru dapat membantu untuk meningkatkan self esteem dan Higher Order Thinking Skills siswa dengan menerapkan model MEA's yang menciptakan sikap menyukai matematika dengan membentuk suasana belajar yang kondusif agar pelajaran menjadi lebih menarik, menantang, menyenangkan dan bermakna.

\section{DAFTAR PUSTAKA}

Anderson, L. W. \& Krathwohl, D. R. 2000. A Taxonomy for Learning, Teaching and Assessing: A Revision of Bloom's Taxonomy of Educational Objectives. A Bridge Edition. New York: Addison Wesley Longman, Inc.

Ariandari, Weindy Pramita. 2015. Mengintegrasikan Higher Order Thinking dalam Pembelajaran Creative Problem Solving. Prosiding Seminar Nasional Matematika dan Pendidikan Matematika UNY. Yogyakarta, 11 November.

Baumeister, Roy F., Campbell, Jennifer D., Krueger, 2 Joachim I., Vohs, Kathleen D. (2003). Does High Self-Esteem Cause Better Performance, Interpersonal Success, Happiness, or Healthier Lifestyles?. Journal of Psychological Science in The Public Interest Vol. 4 (1):1-44

Blankenstain, dkk. 2013. Relevant Prior Knowledge Moderates the Effect of Elaboration During Small Group Discussion on Academic Achievement. Journal of Instructional Science Vol. 41: 729-744

Branden, Nathaniel. 2005. Kekuatan Harga Diri. Batam: Interaksara.

Burrowes. 2003. A Student-Centered Approach to Teaching General Biology That Really Works: Lord's Constructivist Model. Jurnal The American Biology Teacher, Vol 65 No. 7: 491-494

Chamberlin, S. A. 2005. Model-Eliciting Activities as a Tool to Delevop and Identify Creatively Gifted Mathematicians. Journal of Secondary Gifted Education Vol. XVII, No. I: 37-47

Conklin, W. \& Manfro, J. 2012. Strategies for Developing Higher-Order Thinking Skills. Shell Educational Publishing.

Diali, Musmahmud. 2017. "Pengembangan Perangkat Pembelajaran Matematika SMP Kelas VIII Berorientasi HOTS". Tesis, Universitas Negeri Yogyakarta: Tidak diterbitkan.

Djamarah, S.B. 2011. Psikologi Belajar. Jakarta: Rineka Cipta

Fadillah, Syarifah. 2009. "Meningkatkan Kemampuan Representasi Multipel Matematis, Pemecahan Masalah Matematis, dan Self Esteem Siswa SMP dalam Matematika Melalui Pembelajaran dengan Pendekatan Open Ended". Disertasi, UPI Bandung: Tidak Diterbitkan.

Hailikari, T. 2009. Assesing University Students Prior Knowledge Implications For Theory and Practice. Finland: Helsinki University.

Kamila, Ismi Isnani \& Mukhlis. 2013. Perbedaan Harga Diri (Self Esteem) Remaja Ditinjau Dari Keberadaan Ayah. Jurnal Psikologi UIN Sultan Syarif Kasim Riau Vol. 9 No 2:100-112

Kemendikbud. 2016. Peraturan Menteri Pendidikan Dan Kebudayaan Nomor 22 Tahun 2016 Tentang Standar Proses Pendidikan Dasar Dan Menengah. Jakarta: Kementeian Pendidikan dan Kebudayaan.

Lesh dan Doerr. 2003. Problem Solving, Modeling, and Local Conceptual Development. Journal of Mathematical Thinking and Learning Vol. 5(2\&3): 157-189

Lopez, J., and M. Susie Whittington. 2001. Higher-Order Thinking in A College Course: A Case Study. NACTA Journal Vol. 45(4): 22-29

Lubis, Nurul Husna., Pulungan, Putri Su'aidah., Fauzi, M. Amin. 2015. Model Eliciting Activities (MEA) Application in Online Group Discussion for Mathematics Learning. International Journal of Science and Research (IJSR) Vol. 6(7): 1330-1333

Lutan, R. 2003. Self Esteem: Landasan Kepribadian. Jakarta : Bagian Proyek Peningkatan Mutu Organisasi dan Tenaga Keolahragaan Dirjen Olahraga. Depdiknas. 
Manik, Kristina. 2016. "Kemampuan Pemecahan Masalah, Penalaran Dan Self-Esteem Matematis Siswa Smp Melalui Strategi Pembelajaran Metakognitif”. Tesis, UPI Bandung: Tidak diterbitkan.

Mardini. 2008. "Pengaruh Pembelajaran Kontekstual Dan Konvensional Terhadap Keterampilan Komunikasi Terapeutik Ditinjau Dari Tingkat Pengetahuan Awal”. Tesis, UNS Surakarta: Tidak diterbitkan.

Mahmud. 2010. Psikologi Pendidikan. Bandung: Pustaka Setia

Mendikbud. "UN 2021 Digantikan Asesmen Kompetensi Minimum (AKM), Apa yang Berubah?". [Online]. https://www.zenius.net/blog/un-asesmen-kompetensi-minimum-akm. Pada 15 Oktober 2021 pukul 20.00 WIB

Muhadi, Adi. 2017. "Perbandingan Penerapan Model Eliciting Activities (MEAs) dengan Problem Based Learning (PBL) dalam Pencapaian Kemampuan Komunikasi Matematis dan Berpikir Kreatif Siswa SMA". Tesis, UPI Bandung: Tidak diterbitkan.

Mujis, D., \& Reynolds, D. 2011. Effective teaching. Evidence and practice (3rd edition). London: Sage Publication.

Nurmutia, Halida Eka. 2017. Perbandingan Kemampuan Pemecahan Masalah Matematis Antara Siswa yang Memperoleh Pembelajaran Model Eliciting Activities dan Problem Based Learning Ditinjau dari Gaya Kognitif. Tesis, UPI Bandung: Tidak diterbitkan.

Orth, U., Robins, R. W., \& Widaman, K. F. 2012. Life-Span Development of Self-Esteem and its Effects on Important Life Outcomes. Journal of Personality and Social Psychology Vol. 102 No. 6: 1271-1288

Permana, Yanto. 2011. Mengembangkan kemampuan komunikasi matematis dan disposisi siswa Sekolah Menengah Atas melalui Model-Eliciting Activities. Jurnal PPPPTK BMTI Vol. 3 No. 1: $1-10$

Praptiwi \& Jeffry Handika. 2012. Efektifitas Metode Kooperatif Tipe GI dan STAD Ditinjau dari Kemampuan Awal. Jurnal Penelitian Pembelajaran Fisika, IKIP PGRI, Madiun Vol. 3 No.1: 41-50

Priadana, Benny Widya. 2015. "Pengaruh Model Problem-Based Learning dan Problem-Solving Skills Terhadap Peningkatan Self- Esteem Siswa Kelas VIII". Tesis, UPI Bandung: Tidak diterbitkan.

Rajendran, N. S. 2008. Teaching \& Acquiring Higher-Order Thinking Skills, Theory \& Practice. Universiti Pendidikan Sultan Idris.

Saido, G. A. M., Siraj, S., Nordin, A. B., \& Al-Amedy., O. S. 2015. Teaching Strategies for Promoting Higher Order Thinking: A Case of Secondary Science Teacher. Malaysian Online Journal of Educational Management Vol. 3(4): 16 - 30

Smaldino, S. E. 2012. Intructional Technology \& Media For Learning diterjemahkan oleh Arif Rahman. Jakarta: kencana Prenada Media Group.

Sudrajat 2016. "Pengaruh Pembelajaran Model-Eliciting Activities Terhadap Peningkatan Kemampuan Koneksi Matematis dan Self-Confidence Siswa: Kuasi Eksperimen pada Siswa SMP Negeri 3 Bantarsari”. Tesis, UPI Bandung: Tidak diterbitkan

Suherman, dkk. 2003. Strategi Pembelajaran Matematika Kotemporer. Bandung: Universitas Pendidikan Indonesia.

Thomas, A., and Thorne, G. 2010. How to Increase Higher-Order Thinking. Center for Development and Learning, Metairie, Louisiana. 